\title{
POLYMERIZATION OF HETEROCYCLES RELATED TO BIOMEDICAL POLYMERS
}

\author{
V. A. KROPACHEV \\ Institute of High Molecular Weight Compounds AN, Leningrad, USSR
}

\begin{abstract}
Preparation, properties, and some of the applications of heterochain polymers, related to biologically active or medical materials, are discussed.

Various examples of the polymerization processes of the monomers containing $0, \mathrm{~S}-, \mathrm{N}-$ a.o. heteroatoms in the ring are considered together with some peculiarities of the resulting polymers. The presence of the heteroatoms in the polymer chains makes the latter in many cases related to the native polymers (polysaccharides, polypeptides) if the hydrophilicity (water-solubility), biocompatibility, resolution, destruction ability, and elimination are considered.

On the other hand, these polymers may reveal (depending on the nature of the backbone, presence and position of the functional side groups) physiological activity themselves or induce biocompatibility of the materials formed from them (medical fibres, films etc.). The use of hetero-chain polymers with functional groups as a base for addition of physiological (therapeutical) active substances permits to obtain water-soluble polymers with pharmaceutical properties.

The detailed study of the polymerization mechanism of the heterocyclic monomers permitted to find conditions for the regulation of the molecular parameters and structure of the polymers used for (or investigated as) plasma substituents, alloplastic materials, crioprotectors, drugs, pharmaceutical species etc.

Some examples of the polymerization reactions of the heterocyclic monomers (cyclic oxides, lactones, lactolides, $\mathrm{N}$-carboxyanhydrides, anhydrosugars), leading to the biomedical polymers, are discussed in more detail.

The presence of functional groups in a heterocyclic derivative leads in many cases to significant increase of the proportion of the side or parasite reactions, and, eventually, to the formation of products with relatively low molecular weight. The synthesis of high molecular weight heterochain polymers containing active functional side groups became possible by using of the reactions in polymer chains. As an example the experimental data for the copolymerization of ethylene oxide with epichlorohydrin, glycidole a.o. are given together with the data concerning the corresponding chemical reactions of these copolymers leading to the biologically active polymers. Some of their properties, including the medical-biological characteristics of the high molecular weight derivatives are also discussed.
\end{abstract}

According to the literature the interest in the investigation and use of synthetic macromolecular compounds in biology and medicine is rapidly increasing. Moreover, depending on the speciality of research workers and the problems they wish to solve, very different and sometimes contradicting requirements should be met by polymer substances. A polymer drug, for example, should be present in blood for a long time in order to ensure its prolonged action, but it should not accumulate in organs. A polymer used for surgical sutures or as an internal prosthetic appliance should exhibit high strength but should degrade after a predetermined time interval etc.

These requirements should be met by polymers of high molecular weight and at the same time with relatively labile bonds in the main chain. Hence, the structures of heterochain polymers seem very promising. In this respect the ring-opening polymerization seems to have a great future.

It is natural that in the chemical literature dealing with results of the synthesis of macromolecular compounds by ring opening many papers are concerned with the synthesis and the investigation of polymers exhibiting biological or physiological activity, biocompatibility etc.

\section{POLYETHYLENEIMINE AND ITS DERIVATIVES}

When speaking about possible applications of polymers obtained by the opening of nitrogen-containing rings the following features should be mentioned. As early as 1951 it was proposed to use polyethyleneimine (PEI) for sterilization of various objects and also for preservation of foodstuffs. ${ }^{1}$ It was recommended to add PEI to antibacterial detergents which impart antimicrobic properties to surfaces. PEI was shown to be practically non-toxic. $^{2}$

Reactions in polyethyleneimine chains make it possible to prepare polymers whose biological properties are doubtless of interest for investigators. The simplest representative of polyethyleneamides, polyacetylethyleneimine:<smiles>CCCN1CCCC1=O</smiles>

is prepared by acetylation of polyethyleneimine. As early as $\mathbf{1 9 5 7}$ this polymer was recommended for use as plasma substitute, detoxicating agent and depot-preparation of medicines. However, no data are available on further medico-biological studies of this substance.

Lidak and Giller in 1962 were the first to achieve a significant success in studies aimed to prepare polymer antitumor alkylating agents. ${ }^{3}$ They carried out the polymerization of the known antitumor compoundethoxene. The polymer obtained was highly active and less toxic than the starting monomer. Later on it was established by Krentsel, Korschak and Tyurina ${ }^{4}$ that the polymerization of ethoxene occurs both at double bonds and by ring opening. In fact, copolymers are obtained which differ in the ratio of monomer units determined by the conditions used.

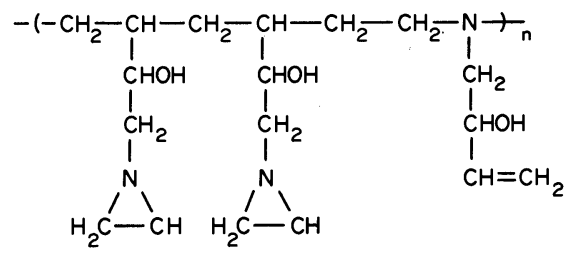

Fig. 1. 
It is likely that two units enter the polymer chain because of the cleavage of the $\mathrm{C}=\mathrm{C}$ bond and one unit because of the ring opening.

Avetyan and Matsoyan were the first to synthesize $N$ (2-chloroethyl)-ethyleneimine, a monomer which represents a combination of two groups possessing high cytostatic activity. ${ }^{5}$ Ring-opening polymerization of ethyleneimine yielded water-soluble polymer antitumorigenic compounds having the structure of $\mathrm{N}$ substituted polyethyleneimine. The monomer is unstable and readily polymerizes in the presence of water. The controlled polymerization was carried out in aqueous dimethylformamide at $30-40^{\circ} \mathrm{C}$. According to the authors the polymerization proceeds through the cationic mechanism by autoinitiation with the participation of quaternary ammonium salt formed from the monomer.

Matsoyan proposed three possible schemes of the polymer chain structure and different kinds of monomer units in it.

$$
\text { t }
$$

Fig. 2.

The mechanism of anti-cancerous action of polychloroimine is not yet clear. Taking into account some distinguishing features of cancer cells it can be assumed, however, that the effectiveness of these polymers results from their combined action both as an active alkylating agent and as a polyelectrolyte.

It is important to note that in this case a higher activity of the polymer structures as compared to the monomers has been established in studying the biological action., ${ }^{6,7}$ At the same time the toxicity of the polymers has been lower than that of all the other derivatives of the chloroethylamine group used in oncologic clinic. Polychloroimine compares favourably with other compounds by the lack of depressive effect in blood formation. It has been shown that the polymer used in therapeutic doses has no influence on blood pressure and breathing. Polychloroimine in amounts of $3 \mathrm{mg} / \mathrm{kg}$ or more shows peripheral and ganglioblocking.

In connection with the discussion of the activity of this type of antitumor drugs it is interesting to notice the following. Recently Kargin and Kabanov and coworkers have published the results of a detailed study of polymer alkylating compounds ad hoc prepared by the reaction of poly-4-vinylpyridine with sarcolysine, carried out on a biochemical level and experimentally. ${ }^{8-10}$ They have shown that the addition of sarcolysine to the polymer through one of the chloroethyl groups of the former does not prevent antitumor activity of these derivatives. This fact should be emphasized as it has been considered for a long time that any replacement of chlorine even in one chloroethyl group of sarcolysine makes it inactive. In the polymer drug we have a different situation because there are always many chloroethylgroups along the polymer chain. Kabanov and coworkers have shown that the activity as well as the manifestation of the short- and long-range influence of chloroethylamine polymer derivatives depend on the character of the comonomer chain, the nature of its functional groups and their amount.

Polyethyleneimine and its derivatives are very interesting substances from the biomedical point of view as synthetic polymers with greater affinity for small molecules than serum albumin. This was discovered by Klotz and co-workers in a series of investigations. ${ }^{11}$

As yet not all the problems are clear of course. Direct correlations between the structure and biological properties cannot yet be established although some trends have already been outlined. And in this connection the possibility of chain structure modification by the introduction of heteroatoms through ring-opening copolymerization looks very promising.

\section{OTHER KINDS OF POLYAMINES}

Polymeric structures of new type of polyamines can be obtained by ring-opening polymerization. This can be illustrated by some examples. With an aim to prepare potential physiologically active compounds containing nitrogen in the main chain, Enikolopyan and Razvodovskii and coworkers were the first to polymerize a number of bicyclic amines. ${ }^{12-14}$ The same authors have synthesized polyamines based on triethylenediamine(I), quinuclidine(II), conidine(III) and 1-azabicyclo-(3,1,0)hexane(IV).

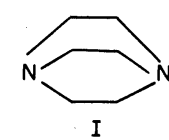

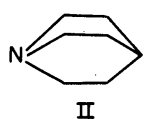

II

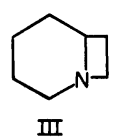

III

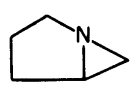

IV
Fig. 3.

Using polyamines prepared from these monomers, the authors have further synthesized polymeric $N$-oxides and shown that they are active as anti-silicosis drugs. ${ }^{15} \mathrm{~A}$ thorough investigation of the polymerization process has made apparent very interesting details of the ring-opening mechanism. It should be noted that the polymerization of such compounds in itself is characterized by a number of significant features. The polymerization process has been thoroughly investigated by Enikolopyan and coworkers. They have shown that the process is initiated under the action of complexing compounds, Lewis acids, metal salts or quartenary ammonium salts. The polymerization follows the pattern seen in "living" polymers.

The following interesting details of the process have been established: the polymerization rate increases with the increase of the size of the counterion in the polymerization by ion pairs; it does not depend on the nature of the counterion in the polymerization by free ions; the activity of free ions is comparable to or is even lower than that of ion pairs.

It has been found that in the case of triethylenediamine(I) the polymerization mechanism can be represented by the following scheme:

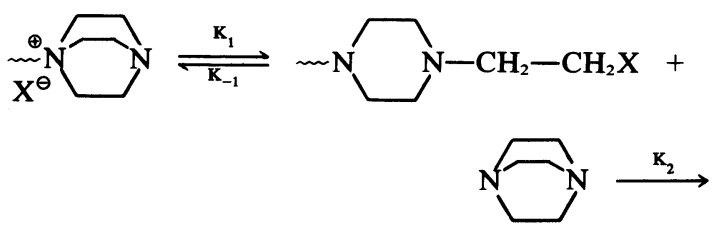


Whereas in the case of conidine (III)...

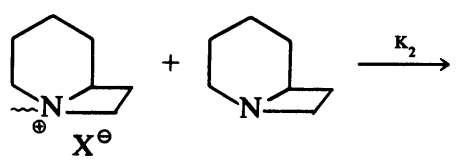

The quaternary polyamine salts can be useful as heparin-antagonists and poly $\mathrm{N}$-oxides as antisilicosis polymeric drugs.

\section{POLYMERS WITH PEPTIDE-, ESTER- AND OTHER TYPES OF BONDS}

Ring-opening polymerization permits the synthesis of chains with polypeptide structure. This is the polymerization of $N$-carboxyanhydrides or Leuchs anhydrides. These compounds have been known since the beginning of our century. Leuchs who discovered them reported that they are able to polymerize. But their polymerization has been widely studied only for the past twenty years. Fundamental investigations of Bamford, Woodworth, Kachalsky, Doty, Goodman and others are widely known. It is natural, since these processes enable us to synthesize model compounds and to study structural and conformational peculiarities of polypeptide chains. Hundreds of polymer structures have already been obtained from carboxyanhydrides both of natural and synthetic $\alpha$-amino acids. Carboxyanhydrides are known to polymerize under various conditions. Water, bases or salts may be used as catalysts. Several schemes of polymerization mechanism have been proposed and work on this problem is now in progress.

Biological activity of polypeptides synthesized by this method is interesting in itself and is being widely investigated. So far there is no definite view on the behavior of these polymers in the organism, on their metabolism, interaction with immune systems etc. As to polymers used in medicine, I will give only one example which is most closely related to the subject of this report. The scheme in Fig. 4 shows the general formula of the ring opening of $\mathrm{N}$-carboxyanhydrides.

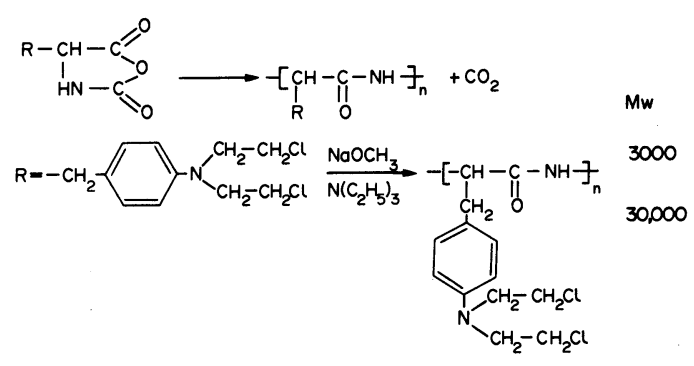

Fig. 4.

The polymerization of carboxyanhydride into which a physiologically active group is introduced as a substituent, yields polymers exhibiting a specific activity. Thus, Mosher and co-workers ${ }^{16}$ carrying out the homopolymerization of $N$-carboxyanhydride of D,Lphenyl alanine containing a group of bis(chloroethyl) amine have obtained a polymer exhibiting antitumor activity. When sodium methylate was used, the polymer had a molecular mass of up to 3000 , and if triethylamine was used, the molecular mass was up to 30,000 .

A comprehensive series of works carried out by Tsuruta and coworkers ${ }^{17}$ is of great interest.

They have shown a possibility of the copolymerization of $N$-carboxyanhydrides with three-membered oxides and $\beta$-lactones. Peptide, urethane, ester and ether bonds are formed in the copolymers. Their ratio may be changed by varying the copolymerization conditions and the catalysts. It has been found that this copolymerization yields water-soluble polymers of high molecular weight with different isotacticity. Further details and pecularities of the process of the polymerization of $N$ carboxyanhydrides by organometallic and other types of catalysts are reported in a paper presented by Tsuruta (Pure Appl. Chem. 48(3), 267-274 (1976). Thorough investigations of this problem, in particular by Tsuruta, ${ }^{17}$ Williams, ${ }^{18}$ Kriecheldorf ${ }^{19}$ and other scientists permit us to hope that this process can be controlled in such a way as to enable us to prepare polymers of the required

(a)
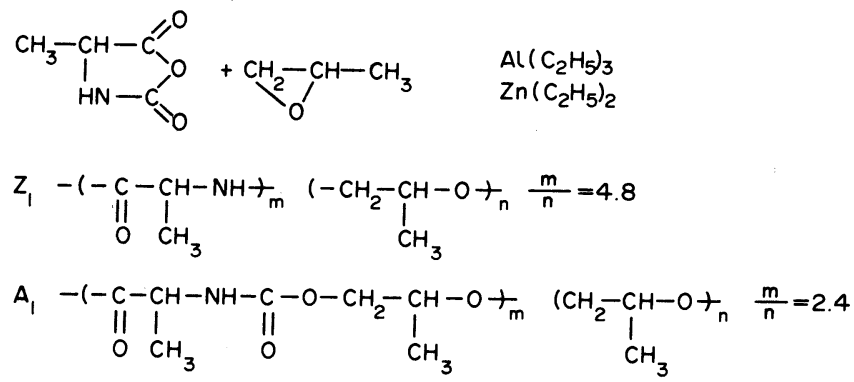

Fig. 5 a.

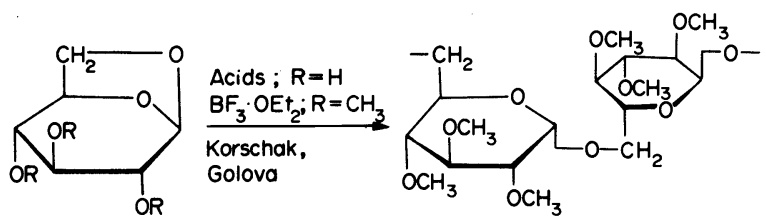

(b)

$$
\frac{\mathrm{PF}_{5} ;-70^{\circ}}{\mathrm{R}=-\mathrm{CH}_{2} \mathrm{C}_{6} \mathrm{H}_{5}} \text { polymer } 42,000-76,000
$$

Fig.5b. 
molecular weight and definite structure. This is one of the most promising way of synthesis of biologically active polymers with regulated activity and regulated time of action. I mean apart from general biological and biochemical aspects, their pharmacological use also becomes important.

\section{SYNTHETIC ANALOGS OF NATURAL SUBSTANCES}

The use of solutions of dextran, a polysaccharide, as plasma substituents and desintoxicators is widely known. Nevertheless, such phenomena as antigenic reactions and haemorrhages make it advisable to investigate methods of synthesis of other polymer derivatives of the polysaccharide class. In particular, the use of ring-opening reactions provides interesting possibilities. Investigations of the polymerization of $\beta$-1,6-anhydroglucopyranose(levoglucosane) are also promising.

$\beta$-1,6-anhydroglucopyranose(levoglucosane) is a cyclic acetal with rings of substituted 1,3-dioxolane and glucopyranose. First attempts to polymerize anhydrosaccharides with ring-opening yielded low molecular products. Water-soluble polymers of levoglucosane with high molecular weight were simultaneously and independently obtained in the USSR by Korshak, Golova and co-workers $^{20}$ and in the USA by Schuerch and coworkers. ${ }^{21}$

As can be seen from the formulas in Fig. 6 the structure of levoglucosane contains $\alpha$-glucoside oxygen bridging bonds similar to those in glycogen. In this respect polymers should be more suitable for metabolism since in organisms of animals and man there are several enzymic systems breaking bonds of this type.

In dextran the oxygen bonds have $\beta$-structures; probably, this determines side reactions of dextrane or its metabolites. The difficulties consist in the fact that catalytic polymerization of rings containing active hydroxyl groups is complicated by termination reaction, chain transfer etc. But the protection of hydroxyl groups is possible.

In 1973, Linderberger and Schuerch ${ }^{22}$ reportéd the synthesis of copolymers containing glucose and maltose units (Fig. 6). This is the first step towards the preparation of regulated structures of polysaccharides by the ringopening method. It should be noted that in order to remove protective groups relatively severe and technically complicated conditions have to be used, such as the treatment by sodium in liquid ammonia. In recent years the processes of opening of 1,3-dioxolane rings have been investigated quite successfully. Various catalytic systems are being studied and we may hope that conditions for the polymerization of dioxolanes of the type of anhydrosaccharides will be found. This will open new paths of the synthesis of polymers which are very promising from the biomedical standpoint.

\section{POLYMERS ON THE ETHYLENE OXIDE BASIS}

Among the plasma substituents used in medical practice a block-copolymer patented in USA is well known:

$$
\begin{gathered}
\mathrm{HO}-\left(\mathrm{CH}_{2}-\mathrm{CH}_{2}-\mathrm{O}-\right)_{m}- \\
\left(\mathrm{CH}_{2}-\mathrm{CH}-\mathrm{O}-\right)_{n}-\left(\mathrm{CH}_{2}-\mathrm{CH}_{2}-\mathrm{O}-\right)_{m}-\mathrm{H} \\
\mathrm{CH}_{3}
\end{gathered}
$$

This is a block copolymer of propylene oxide and ethylene oxide of the ABA type with a molecular weight of 8-10 thousand (trade name Pluronic). Blocks of polyethylene oxide are made of such a length as to ensure the water solubility. The copolymer is used in a saline or Ringer solution. The copolymer is not toxic, is apyrogenic, does not exhibit antigenic properties and is stable in storage. It may be used both for intravenous injections and for filling the heart-lung apparatus. Recently a new method has been described by Hymes for a modification of dialdehyde starch by addition of ethylene glycol or polyethylene oxide $-400 .^{23}$ It is of interest that the polymers obtained are soluble both in water and in organic solvents although bifunctional diols participate in the reaction. The explanation of the authors is that as soon as one hydroxyl end is attached to the polymer, the other end loses its diffusional mobility and cannot approach the aldehyde group of another molecule of dialdehyde starch to form a network. Whether this interpretation is correct, is not clear. However, the polymers themselves in which polyethylene oxide chains with molecular weights of 400 are attached to the polysaccharide chain of the starch by acetal bonds may be of interest as plasma substituent. The authors have proposed a method for coupling diols to aldehydecontaining polymers by treating them with $p$-toluene sulphonic acid in dimethylformamide; this method is of general interest for the preparation of polymers with grafted polyethylene oxide chains of different molecular weight.

Polyethylene oxide and its derivatives may be included in the group of substances widely used in biomedical and the technical side of the medical practice. Thus, polyethylene oxides of different molecular mass are used as cryoprotectors, for freezing and storage of bone marrow, tissues, organs etc. These problems are being widely investigated and a search of new more effective structures is required.

A monograph by N. S. Pushkar and A. M. BelousIntroduction into Cryobiology, has recently been pub-

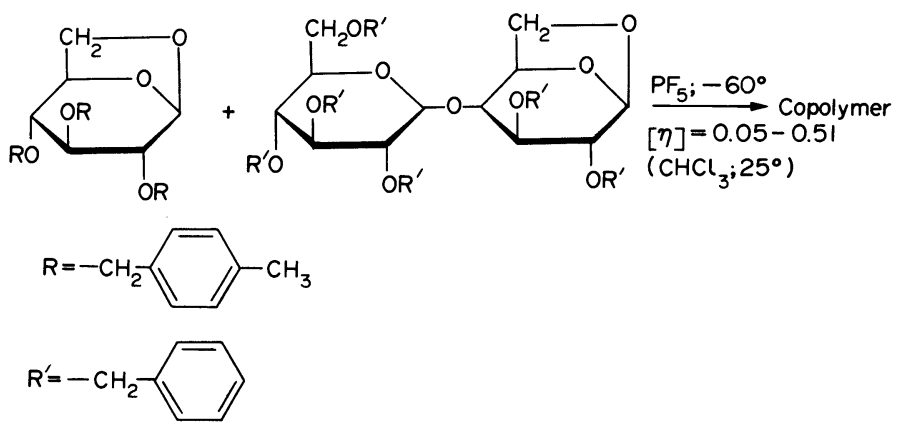

Fig. 6. 
lished in the USSR (1975). It deals in particular with specific properties of polyethylene oxides as a polymer system actively influencing biologically bonded water. This property is also important for maintaining homeostasis when polymers are used as plasma constituents and solutions in apparatus for extracorporeal blood circulation.

A class of nonionic surface-active substances is very interesting from the biomedical standpoint. Derivatives of ethylene oxide synthesized by the opening of epoxide rings are characteristic of substances of this type. The most widely known among them have trade-marks "Tweens" and "Tritons". They are oligomeric polyethylene oxides with hydrophobic units or sequences in their structure.

In 1951 a group of English scientists accidentally found that Triton, an industrial detergent, exhibits an exceptionally high ability to suppress the course of an acute tubercular infection in mice. But its toxicity was too high Sufficiently. active and much less toxic compounds have been found among its analogs synthesized later.

The general formula of these compounds is:

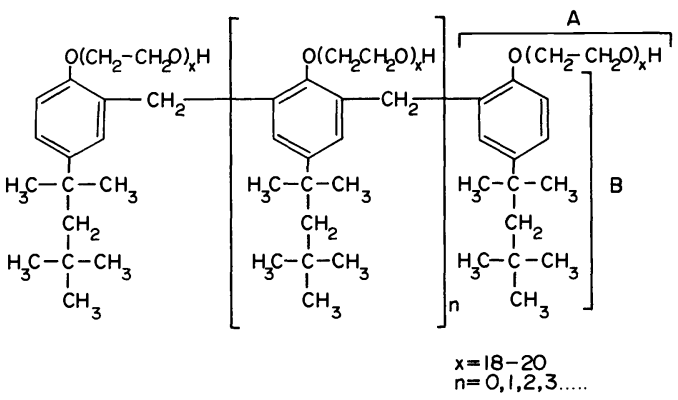

Fig. 7.

As a result of a long search a compound called "macrocyclone" has been found. There are four phenol groups in its structure and the average number of units of ethylene oxide is twelve. Its total molecular weight is about 4000. "Macrocyclone" was not absorbed in the stomach and should be introduced parenterally. Its antitubercular action was similar to that of streptomycin. It was not toxic and was highly active in experiments with mice, rats and rabbits.

This series of investigations yielded much useful information concerning the behavior of oligomers nonionic surface-active substances in organisms and their effect on mycobacteria. Tritons were found to act very selectively. They are accumulated in monocytes and change the surface of mycobacteria of tuberculosis in such a way that the cell kills them rapidly. Unfortunately clinical investigations of the effect of "macrocyclone" on human patients have shown that the compounds are not active even in large doses.

Nevertheless, polymers of the triton type proved to be interesting from other standpoints. Biochemists study intensively their significance in the lipid metabolism. For example, Klimov and co-workers published some reports $^{25}$ in this field.

The mechanism of action of Tritons is very well known. The introduction of Triton increases the rate of the biosynthesis of cholesterol and its content in blood. The introduction of Tritons can model hyperlipaemia(obesity). This helps biochemists ${ }^{25}$ to find new drugs for fighting this disease.
Tweens are also detergents widely used in biomedical practice. They are derivatives of polyoxyethylene and anhydrosorbitol esters. Several trade-marks of Tweens are manufactured, differing in the nature of the fatty acid and the length of polyoxyethylene chains. Their general formula is:

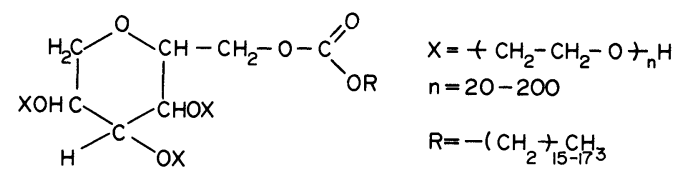

Fig. 8.

These nonionic detergents are used for the solubilization and introduction into the human organism of a number of insoluble medicines: vitamins, antibiotics etc. It was established that detergents based on polyethylene oxide intensify the action of some antitumor agents, prolong the action of antitubercular drugs etc. In contrast to triton, they are not toxic.

Polyethylene oxide chains appear very promising for obtaining physiologically active polymers. Their main advantages are hydrophilicity and degradation ability.

The aim of our work was to synthesize physiologically active polymers based on polyethylene oxides. One path was the bonding of well known medicinal drugs to the polymer chain, the other part consisted in a search of structures of polymers exhibiting inherent biological activity. In order to carry out reactions in chains of polyethylene oxide it was necessary to develop methods to introduce into the chains functional groups of various nature. We selected as the main compound the copolymer of ethylene oxide with epichlorohydrin. In collaboration with Alferova and Kurengina we have shown ${ }^{26,27}$ that by using the catalytic system triethylaluminium-waterelectron donor it is possible to obtain copolymers in good yield with relatively high intrinsic viscosities and regulated content of epichlorohydrin units.

Conditions of modification were developed and corresponding derivatives were obtained.

Figure 9 shows the structures of the copolymer chain and of some reagents.

Figure 10 shows the structures of the ethylene oxide copolymers under investigation.

The investigation of reactions in copolymer chains has shown for example that imidazole and its derivatives degrade the chains of polyethylene oxide and its copolymers at $80^{\circ}$ both in polar (dimethylformamide) and in nonpolar (benzene) solvents.

Investigations of properties of solutions of polyethylene oxide show that this polymer exhibits some peculiarities: it is able to change the conformation both of its own chain and of many other polymers in solution.

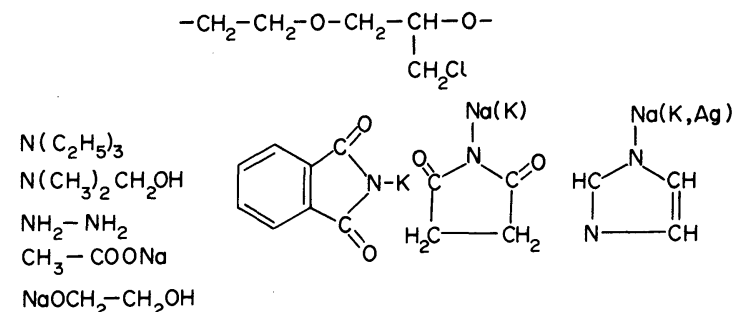

Fig. 9. 


$$
\begin{aligned}
& \mathrm{R}=\begin{array}{lll}
-\mathrm{CH}_{3} & -\mathrm{CH}_{2}-\mathrm{CH}_{2}-\mathrm{OH}_{\mathrm{m}}-\left(-\mathrm{CH}_{2}-\mathrm{CH}-\mathrm{O}+\mathrm{T}_{\mathrm{n}}\right. \\
-\mathrm{CH}_{2} \mathrm{Cl}(\mathrm{Br}) & -\mathrm{CH}_{2} \mathrm{NH}_{2} & -\mathrm{CH}_{2}-\mathrm{R}_{2} \\
-\mathrm{CH}_{2} \mathrm{OH} & -\mathrm{CH}_{2} \mathrm{NH}_{-}-\mathrm{NH}_{2} & -\mathrm{CH}_{2}-\mathrm{N}
\end{array} \\
& -\mathrm{CH}_{2} \mathrm{OH} \\
& \text { - } \mathrm{CHO} \\
& -\mathrm{CH}_{2} \mathrm{COOR} \\
& -\mathrm{CH}_{2}-\mathrm{OCH}_{2} \mathrm{CH}_{2} \mathrm{OH} \\
& -\mathrm{CH}_{2}-\left[\mathrm{N}\left(\mathrm{C}_{2} \mathrm{H}_{5}\right)_{3}\right]^{\mathrm{C}} \mathrm{Cl}^{-} \\
& -\mathrm{CH}_{2}-\mathrm{N}= \\
& \begin{array}{l}
-\mathrm{CH}_{2}-\left[\mathrm{N}-\left(\mathrm{CH}_{3}\right)_{2}\right. \\
-\mathrm{CH}_{2} \mathrm{CH}_{2} \mathrm{OH}-\mathrm{CH}-\mathrm{C}-\mathrm{CH}_{3} \\
0
\end{array}
\end{aligned}
$$

Fig. 10 .

This was shown in works of Papisov and Kabanov in Moscow University. ${ }^{28}$ Polyethyleneoxides are also investigated as complexing agents for drugs by Kono and Takeda and coworkers. ${ }^{29}$

Previously it was possible to bind physiologically active substances only to end groups of polyethylene oxide. Topchieva and Kabanov have found that these polymers are very interesting as models of biocatalysts. ${ }^{30}$

Weiner and Zilcha in 1973 have shown that the attachment of procaine to endgroups of polyethylene glycol-400 leads to an anesthetic of a more prolonged action. But it was found that derivative of tetraethylene glycol is characterized by an even more prolonged action. $^{31}$

Copolymers which we synthesized permit the introduction into polyethylene oxide chains of much greater amounts of physiologically active groups. A combination of specific hydrophilic-hydrophobic properties of polymer derivatives of $\alpha$-oxides is responsible for their peculiar behaviour in processes of sorption and permeation through biological membranes.

Hence, it might be expected that new useful possibilities of their use will be found.

Our data even show that some copolymers of ethylene oxide which do not include specific pharmacologically active groups, exhibit pharmacological action. They are not toxic, ensure haemodynamic effect at low concentrations etc. When pharmacologically active groups are introduced into these polymers, their action is retained.

\section{THE POLYNUCLEOTIDE MODELS}

In order to understand processes of the interaction of natural and synthetic polymers introduced into the organism with its enzymic systems, cells, organs etc., it is important to investigate individual aspects of the problem by using model systems. In particular, polymers modelling structures of nucleic acids are required.

Interesting investigations are in progress at the Riga Institute of Organic Synthesis by the Academician Giller's school. He has proposed and developed a method for the preparation of synthetic analogs of nucleic acids by the condensation of corresponding diols. At first, relatively simple structure were synthesized and later oligomeric polynucleotides complementary to natural amino acids were prepared. $^{32}$

Figure 11 shows a part of the RNA chain and structures of model polymers.

Methods of ring-opening polymerization also give a possibility of obtaining similar structures. One of these methods is being developed by Penczek and co-workers. ${ }^{33}$ The polymerization is carried out in the presence of hexafluorophosphate carbenium salts and 2-methoxy-2-

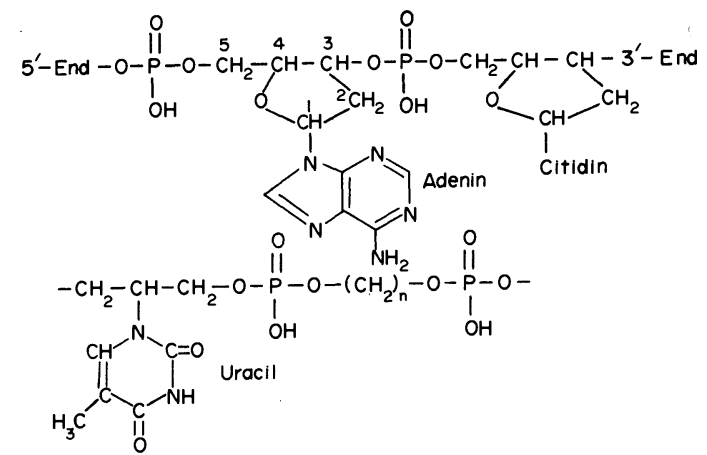

Fig. 11a.

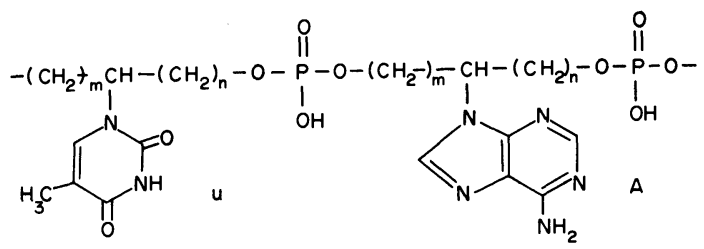

Fig. 11b.

oxo-1,3-2-dioxaphosphorinane (MODP) is used as monomer (Fig. 12).

It is clear that in both cases models are much simpler than chains of natural nucleic acids. However, it is known that in some cases single functions of complex natural polymers are relatively well modelled by simple polymer structures. Moreover, the development of methods for the synthesis of monomers and polymers indicates that even more complex structures will be obtained.

One of the purposes of this research is the synthesis of pharmacologically active polymer drugs. Thus, the investigation of polymer analogs of natural macromolecules with the aim of suppressing selective action of RNA-polymerase has shown that polymers of specific structure and configuration may inhibit protein synthesis and stop the growth of malignant tumors. It has been suggested that it is much easier for these "depressing" polymers than for low molecular chemo-therapeutic substances to "recognize" by some of their elementary units the corresponding center of the enzyme suitable for attack, and to block its activity.<smiles>COP1(=O)OCC2CCCOP2(=O)O1</smiles>

Fig. 12. 


\section{CONCLUSIONS}

We think that polymeric drugs based on copolymers of cyclic oxides and other heterocycles may be promising for several purposes, for example.

1. In those cases when it is necessary to use polymers of higher molecular weight for example to have depotseffects and at the same time to ensure their subsequent degradation and removal from the organism.

2. For the preparation of gel or crosslinked structures which can be degraded in the organism by an attack both on the crosslinking units and on the main polymer chain.

3. When it is necessary to ensure the formation of a complex with low or high molecular physiologically active substances by introducing into the polymer chain a large number of atoms and groups with the complexing ability or with the specific biological activity.

Thus, when we consider investigations concerning the synthesis and investigations of physiologically active polymers, we can note that most of them are as yet on the level of primary biological screening. This stage is inevitable and useful. It permits us to develop possibilities to select definite substances or even homologous series for more profound pharmacological and, later, clinical studies. Now the time has come for a thorough investigation of polymers of different structures on the biochemical, histochemical and molecular-biological level. These investigations are already in progress. Some of them give valuable material for comprehending the action of low molecular chemo-therapeutic drugs. Specific properties of macromolecules which do not contain deliberately pharmacologically active units are being investigated.

And once more drugs of polymeric nature have been found and they must be studied by special pharmacological methods, I believe.

\section{REFERENCES}

${ }^{1}$ C. Scholler, German Pat. 802346 (1951).

${ }^{2}$ P. A. Gembickij, D. S. Shuk and V. A. Kargin, Poliethilenimin. p. 182, Moscow (1971).

${ }^{3}$ M. Yu. Lidak and S. A. Giller, Puti Sinteza $i$ Iziskanija Protivoopucholevich Preparatov. p. 150, Moscow (1962).

${ }^{4}$ B. A. Krentzel, Yu. V. Korschak and E. P. Tyurina, Puti Sinteza i Iziskanija Protivoopucholevich Preparatov. p. 113, Moscow (1967).

${ }^{5}$ M. G. Avetjan and S. G. Matsojan, I-ja Vsesoyuznaja Konferentsia po Chimioterapii Zlokatchestvennich Opucholej. p. 106, Riga (1968).

'I. G. Demirchogljan, S. A. Papojan, O. V. Babasjan, S. A. Wardanjan and D. A. Galstjan, I-ja Vsesoyuznaya Konferentsia po Chimioterapii Zlokatchestvennich Opucholej. p. 253, Riga (1968).

'D. A. Galstjan, Vopr. Rentgenol. Onkol. 8, 239 (1965).
${ }^{8}$ O. V. Zubova, L. I. Samoilovich, A. A. Schorochova, Yu. E. Kirsch, T. S. Lebedeva, A. B. Silaev and V. A. Kabanov, 3 Simposium po Fisiologitscheski Aktivnium i Sintetitscheskim Polimeram i Modelnim Biopolimeram. p. 5, Riga (1971).

${ }^{\circ}$ O. V. Zubova, Yu. E. Kirsch, T. S. Lebedeva, A. A. Schorochova, A. B. Silaev, V. A. Kabanov and V. A. Kargin, Dokl. Akad. Nauk SSSR, 186, 477 (1969); 198, 710 (1971).

${ }^{10} \mathrm{O}$. V. Zubova and Yu. E. Kirsch, Aktual. vopr. Sovremen. Onkol. 3, 260 (1973).

${ }^{11}$ I. M. Klotz and A. R. Sloniewsky, Biochem. Biophys. Res. Comm. 31(3), 421 (1968).

${ }^{12}$ E. F. Razvodovskij, L. M. Putschaeva and N. S. Enikolopjan, Vysokomol. soed. 75 (1970).

${ }^{13}$ E. F. Razvodovskij, A. V. Nekrasov, A. A. Berlin and A. T. Ponomarenko and N. S. Enikolopjan, Dokl. Akad. Nauk SSR 198, 894 (1971).

${ }^{14}$ I. S. Morozova, E. F. Razvodovskij, A. V. Nekrasov, M. A. Markevitch, Al. Al. Berlin, S. P. Petrosjanz, W. A. Afanasjev, V. S. Bogdanov and N. S. Enikolopjan, Dokl. Akad. Nauk SSSR 209, 153 (1973).

${ }^{15}$ E. F. Razvodovskij, A. V. Nekrasov, L. M. Putschaeva and N. S. Enikolopjan, 3 Simposium po Fisiologitscheski Aktivnim $i$ Sintetitscheskim Polimeram i Modelnim Biopolimeram. p. 61, Riga (1971).

${ }^{16}$ C. W. Mosher, R. H. Iwamoto, E. M. Acton and L. Goodman, J. Med. Chem. 7, 650 (1965).

${ }^{17} \mathrm{~T}$. Tsuruta, S. Inoue, M. Yoneyama and N. Yamada, Makromol. Chem. 110, 133 (1967); T. Tsuruta, S. Inoue and K. Matsuura, J. Polymer Sci. C22, 981 (1969).

${ }^{18}$ F. D. Williams and R. D. Brown, Makromol. Chem. 169, 191 (1973).

${ }^{19}$ H. R. Kriecheldorf, Makromol. Chem. 173, 13 (1973).

${ }^{20}$ V. V. Korschak, O. P. Golova, W. A. Sergeev, N. M. Merlis and R. Ja. Schneer, Vysokomol. soed. 3, 474 (1961).

${ }^{21}$ I. Da Silva Carvalho, W. Prins and C. Schuerch, J. Am. Chem. Soc. 81, 4054 (1958).

${ }^{22}$ W. H. Linderberger and C. Schuerch, J. Polymer Sci., Poly. Chem. 11, 1226 (1973).

${ }^{23}$ A. C. Hymes, U.S. Pat, 3,590,125 (1971).

${ }^{24}$ N. S. Pushkar and A. M. Belous, Vvedenie v Criobiologiju. Kiev (1975).

${ }^{25}$ A. N. Klimov, T. A. Klimova, E. D. Poljakova, E. B. Dige and L. A. Petrova, Voprosi med. chimii 20, 65 (1974).

${ }^{26}$ T. N. Kurengina, L. V. Alferova and V. A. Kropachev, Vysokomol. soed. A11, 1985 (1969).

${ }^{27}$ T. N. Kurengina, L. V. Alferova and V. A. Kropachev, Vysokomol. soed. B15, 885 (1973).

${ }^{28}$ I. M. Papisov, V. A. Kabanov, V. Yu. Baranovskii, V. YaChernjak and A. D. Antipina, Dokl. Akad. Nauk SSSR 199, 1364 (1971).

${ }^{29}$ K. Kono and Y. Takeda, Chem. Pharm. Bull. 22, 165 (1974).

${ }^{30}$ I. N. Toptshieva, A. B. Solovjeva and V. A. Kabanov, Dokl. Akad. Nauk SSSR 199, 1084 (1971).

${ }^{31}$ B. Weiner and A. Zilkha, J. Med. Chem. 16, 573 (1973).

${ }^{32}$ S. A. Giller, I-ja Vsesojuznaja Konferensija po Chiliterapii Zlokatchestvennich Opucholuj. p. 20, Riga (1968).

${ }^{33}$ G. Lapienis and St. Penczek, Macromolecules 7, 166 (1974). 